\title{
STUDY ON ROLLING PROCESS AND HEAT TREATMENT OF HIGH STRENGTH SHIP PLATE STEEL EH40
}

\author{
Chunquan Liu*, Qichun Peng, Zhengliang Xue \\ The State Key Laboratory of Refractories and Metallurgy, Key Laboratory for \\ Ferrous Metallurgy and Resources Utilization of Ministry of Education, Wuhan \\ University of Science and Technology, Wuhan 430081, China
}

Received 07.07.2018.

Accepted 18.10.2018.

\begin{abstract}
Means of a tensile test studied the mechanical properties and microstructure of the experimental steel plate under different rolling processes, Charpy impact test, optical microscopy and scanning electron microscopy (SEM). The results show that the optimum thermomechanical control process (TMCP) is a heating temperature of $1200{ }^{\circ} \mathrm{C}$, the best rolling temperature of $1180^{\circ} \mathrm{C}$. The thickness of the ship plate steel was rolled from 170 $\mathrm{mm}$ to $40 \mathrm{~mm}$ in the recrystallization zone by multi-channel time deformation, and then the thickness was decreased from $40 \mathrm{~mm}$ to $15 \mathrm{~mm}$ in the non-recrystallization zone, the temperature waiting for a range $980{ }^{\circ} \mathrm{C} \sim 920^{\circ} \mathrm{C}$, the finish rolling temperature of 830 ${ }^{\circ} \mathrm{C}$. After rolling and being cooled rapidly by laminar cooling, the cooling rate is about $12{ }^{\circ} \mathrm{C} / \mathrm{s}$ and the final target temperature of $600{ }^{\circ} \mathrm{C}$, which maintains the best state of steels. All data of the experimental steels have accelerated the international level, high-strength ship plate EH40 has been successfully trialed and met the practical requirements, all of these provide a solid foundation for further scientific research.
\end{abstract}

Keywords: EH40 shipbuilding steel; thermomechanical control process TMCP; mechanical microstructure properties.

\section{Introduction}

In recent years, the ship's maximization, high-Speeding, and development of offshore oil-gas fields have provided a broad practical prospect for high-strength hull structural steel [1-4]. It is necessary to study the development trend and production technology of plate steel. High strength shipbuilding steel was divided into three intensity levels: $32 \mathrm{~kg}, 36 \mathrm{~kg}$, and $40 \mathrm{~kg}$. According to the different impact toughness, each level of high strength ship steel was classified into four grades: $\mathrm{AH}, \mathrm{DH}, \mathrm{EH}$, and $\mathrm{FH}$, that are,

* Corresponding author: Chunquan Liu, liuchunquan@wust.edu.cn 
AH32 FH32, AH36 FH36, AH40 FH40 [5-7]. A new generation of China shipbuilding EH40 steel can withstand high heat input welding of fine grain high strength micro-alloyed steel, which was based on low carbon and low sulfur, adding appropriate $\mathrm{Nb}, \mathrm{Ti}$, and other alloying elements, combined with controlled rolling and cooling heat treatment technology to obtain [8]. EH40 high strength ship plate not only requires high strength but also has higher requirements on low-temperature toughness and weldability. The design principle of EH40 is to adopt the low carbon micro-alloyed component system, combined with reasonable steel making, continuous casting and controlled rolling-cooling process. In order to develop the high additional value steel plate, the new TMCP technology of high strength shipbuilding steel plate was proposed by scholars, to improve the technical level and market competitiveness of plate products.

In this paper, the composition of EH40 steels was designed by analyzing the influence of the composition of molten steel on steels and the composition control range of EH40 high strength ship plate steel by classification societies. The EH40 ship plate steel was simulated by vacuum induction furnace to be controlled within the target range. A most reasonable rolling process and a heat treatment process were explored, and the EH40 steel of low cost, low energy consumption, short process production in the laboratory is achieved by three different TMCP and the heat treatment after the rolling. The product is put into the production line, and then will be certified by the multinational classification society through efforts on scientific studies.

\section{Experimental}

The chemical composition of the EH40 high strength shipbuilding steel is presented in Table 1 . A $50 \mathrm{~kg}$ of vacuum induction melting was used to prepare experimental steel ingot which was then forged into $170 \mathrm{~mm}$ steel plates. Afterward, the ingot with a thickness of $170 \mathrm{~mm}$ was homogenized at $1200{ }^{\circ} \mathrm{C}$ for $2 \mathrm{~h}$ and initially rolled to $40 \sim 55 \mathrm{~mm}$-thick plates via 7 passes between $1180{ }^{\circ} \mathrm{C}$ and $980{ }^{\circ} \mathrm{C}$, and then finishing rolled to $15 \sim 40 \mathrm{~mm}$ - thick plates via 3 passes between $930 \sim 910{ }^{\circ} \mathrm{C}$ and $850{ }^{\circ} \mathrm{C}$, and subsequently quenched to $600 \sim 560^{\circ} \mathrm{C}$ with an average cooling rate of $12{ }^{\circ} \mathrm{C} / \mathrm{s}$, and then air cooling to room temperature (as shown in Fig. 1). The rolling process and the ingot specifications are shown in Table 2.

Table 1 Chemical composition of the EH4O high strength shipbuilding steel (wt. \%).

\begin{tabular}{lcccccccc}
\hline & $\mathrm{C}$ & $\mathrm{Si}$ & $\mathrm{Mn}$ & $\mathrm{P}$ & $\mathrm{S}$ & $\mathrm{Als}$ & $\mathrm{Nb}$ & $\mathrm{Ti}$ \\
\hline Ingot 1 \# $\left(\mathrm{I}_{1}\right)$ & 0.074 & 0.308 & 1.310 & 0.0042 & 0.0025 & 0.0280 & 0.038 & 0.016 \\
Ingot 2 \# $\left(\mathrm{I}_{2}\right)$ & 0.082 & 0.305 & 1.330 & 0.0080 & 0.0050 & 0.0239 & 0.031 & 0.012 \\
Ingot 3 \# $\left(\mathrm{I}_{3}\right)$ & 0.088 & 0.314 & 1.355 & 0.0070 & 0.0055 & 0.0240 & 0.034 & 0.014 \\
\hline
\end{tabular}


Table 2 Rolling process and specification of steel ingot.

\begin{tabular}{ccccccccc}
\hline & $\begin{array}{c}\text { Unif. } \\
\text { temp. } \\
/{ }^{\circ} \mathrm{C}\end{array}$ & $\begin{array}{c}\text { Rough } \\
\text { rolling } \\
\text { initial } \\
\text { temp. / } \\
{ }^{\circ} \mathrm{C}\end{array}$ & $\begin{array}{c}\text { Rough } \\
\text { rolling } \\
\text { end } \\
\text { temp. / } \\
{ }^{\circ} \mathrm{C}\end{array}$ & $\begin{array}{c}\text { Rough } \\
\text { rolling } \\
\text { thickness } \\
/ \mathrm{mm}\end{array}$ & $\begin{array}{c}\text { Finishing } \\
\text { rolling } \\
\text { initial } \\
\text { temp. } \\
/{ }^{\circ} \mathrm{C}\end{array}$ & $\begin{array}{c}\text { Finishing } \\
\text { rolling end } \\
\text { temp. } /{ }^{\circ} \mathrm{C}\end{array}$ & $\begin{array}{c}\text { Second stage } \\
\text { of outcome } \\
\text { thickness } \\
\text { arrangement } \\
/ \mathrm{mm}\end{array}$ & $\begin{array}{c}\text { Ultimate } \\
\text { cooling } \\
\text { temp. / } \\
{ }^{\circ} \mathrm{C}\end{array}$ \\
\hline $\mathrm{I}_{1}$ & 1200 & 1180 & 980 & 40 & 930 & 850 & $30,20,15$ & 600 \\
$\mathrm{I}_{2}$ & 1200 & 1180 & 980 & 40 & 910 & 850 & $30,21,15$ & 560 \\
$\mathrm{I}_{3}$ & 1200 & 1180 & 980 & 55 & 910 & 850 & $40,30,21,15$ & 560 \\
\hline
\end{tabular}

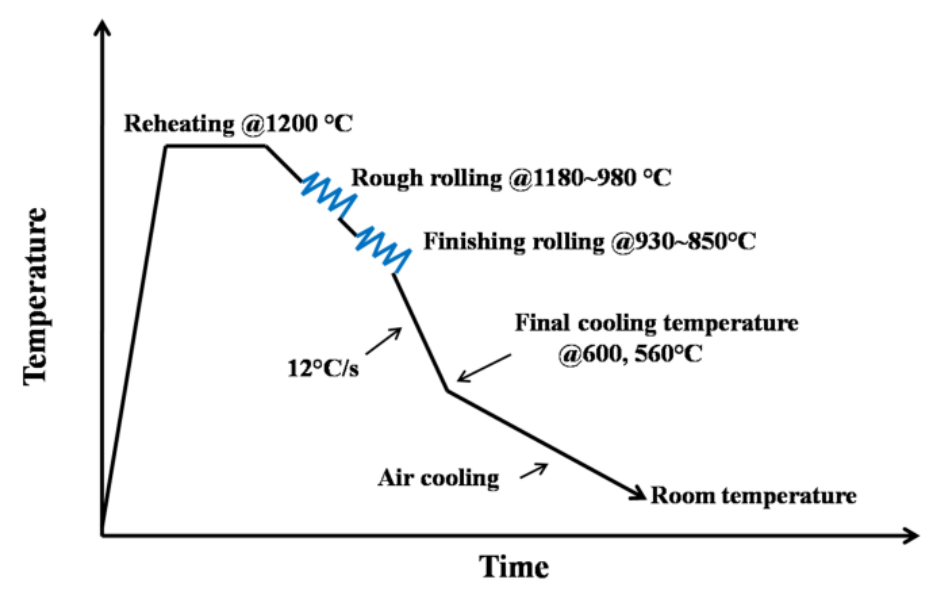

Fig. 1. Schematic of the thermo-mechanical treatment for the experimental steel.

The rolled steel plate of $\mathrm{I}_{1}$ was divided into two pieces, marked $\mathrm{EH} 1$ and $\mathrm{EH} 2$, respectively, the EH1 did not do other processing while the EH2 by normalizing treatment. Both of them were heated 30 minutes and preservation for 5 minutes with a uniform temperature of $910^{\circ} \mathrm{C}$. The rolled steel plate of $\mathrm{I}_{2}$ and $\mathrm{I}_{3}$ were marked as EH3 and EH4. Tensile specimens were machined to a standard GB/T 228-2010 size of $12.5 \mathrm{~mm}$ width and 50mm gauge length along the rolling direction. According to GB228/2002, 10 $\mathrm{mm} \times 10 \mathrm{rm} \times 55 \mathrm{~mm}$ standard Charpy V-type impact specimens were prepared in the rolling direction, and a transverse direction and the low-temperature impact work (-20, $-40,-60{ }^{\circ} \mathrm{C}$ ) was measured. After the samples were ground, polished and etched, the microstructure was observed by XJL-024 optical microscope and Quanta 400 scanning electron microscope.

\section{Results and Discussion}

\section{Mechanical properties}

The transverse and longitudinal tensile properties of EH40 ship plate steels in four different rolling and heat treatment processes shown in Table 3. It's clear that the difference of yield strength and tensile strength between the four kinds of rolled plates is not evident in the transverse and longitudinal direction, The EH2 normalizing treatment of the yield strength and tensile strength did not meet the national standard requirements, which provides EH40 ship plate yield strength $(\geq 390 \mathrm{MPa})$ and tensile strength $510 \mathrm{MPa}$ $\sim 660 \mathrm{MPa}$. In contrast, the rolling samples of EH1, EH3 and EH4 transverse and 
longitudinal tensile strength has accelerated the international minimum limitation of 510 $\mathrm{MPa}$ and the international limitation of yield strength $390 \mathrm{MPa}$, in which the rolling sample of EH1 transverse tensile strength is close to its maximum limit of $660 \mathrm{MPa}$. Table 3 showed the elongation and reduction of the area of the four kinds of steel plates in the transverse and longitudinal directions. It indicates that the transverse and longitudinal elongation of the four kinds of steel plates are higher than those of the GB712-2000 provisions of high-strength ship plate steel elongation not less than 20\%, although there is no specific international comparative value of reduction of area, these four sections of the steel sheet reduction of area all have a high section shrinkage as more than $70 \%$.

It is concluded that the properties of the rolling samples of EH1, EH3, and EH4 can meet the international standards. However, the Reduction of area and Elongation of the rolling and normalizing treatment of $\mathrm{EH} 2$ process is higher than that in the other three kinds of rolled steel sheets, the yield strength and tensile strength are lower than the international value, and it does not meet the experimental requirements. The yield strength and tensile strength of the EH1 rolled steel sheet are the highest among these four processes, reaching 540MPa and 620MPa (GB712-2000), respectively. This reveals that $\mathrm{EH} 1$ has better tensile properties under the rolling process.

The impact toughness test applied the standard Charpy V-type impact test, the impact toughness of the EH40 shipboard steel test of the four processes are shown in Table 3. It indicates that the impact toughness of four kinds of rolled steel plates is under $-20{ }^{\circ} \mathrm{C},-40{ }^{\circ} \mathrm{C}$ and $-60{ }^{\circ} \mathrm{C}$ which is higher than the national standard value. The EH2 rolling and normalized steel specimens of transverse and longitudinal impact toughness are highest, followed by EH1, explaining normalizing treatment can improve the impact toughness of EH40 steel. This is because, in the normalizing treatment, the part of the precipitated particles will be re-dissolved, in the subsequent cooling process, the normalizing cooling rate is not high, the organization tends to balance, grain has been gradually refined, and the grain boundary increased, the diffusion distance and conditions of the precipitated material has been improved, Therefore, a part of precipitates which are inhibited at a high cooling rate is likely to precipitate, and the positions where the precipitated particles can nucleate are increased, so that the precipitated second phase particles are refined, small and uniform ferrite structure and massive distribution of pearlite are obtained, that the impact toughness of ship plate steel has been improved. Also, through the normalizing treatment, the coarse Widmanstatten Structure and the black unbalanced structure existing in the TCMP process of the experimental steel can be eliminated, and by refining the grain, we can significantly improve the impact property of the steel plate. 
Table 3. Mechanical properties of EH40 steel plate.

\begin{tabular}{|c|c|c|c|c|c|c|c|c|}
\hline & & $\begin{array}{l}\mathrm{R}_{\mathrm{eL}} \\
\mathrm{MPa}\end{array}$ & $\begin{array}{l}\mathrm{Rm} \\
/ \mathrm{MPa}\end{array}$ & $\mathrm{A}_{80 \mathrm{~mm}}(\%)$ & Z (\%) & $-20^{\circ} \mathrm{C}$ & $\begin{array}{c}\mathrm{IE} \\
(\mathrm{Akv} / \mathrm{J}) \\
-40^{\circ} \mathrm{C}\end{array}$ & $-60{ }^{\circ} \mathrm{C}$ \\
\hline \multicolumn{2}{|c|}{ National standard } & $\geq 390$ & 510 660 & $\geq 20$ & $\geq 25$ & $\geq 41$ & $\geq 41$ & $\geq 41$ \\
\hline \multirow{4}{*}{$\begin{array}{l}\text { cross- } \\
\text { section }\end{array}$} & EH1 & 540 & 620 & 24.5 & 71.0 & 196 & 184 & 159 \\
\hline & $\mathrm{EH} 2$ & 377 & 482 & 35.2 & 77.8 & 313 & 313 & 278 \\
\hline & EH3 & 492 & 580 & 24.8 & 71.0 & 170 & 159 & 109 \\
\hline & EH4 & 442 & 543 & 287 & 76.3 & 170 & 177 & 130 \\
\hline \multirow{4}{*}{$\begin{array}{l}\text { Vertical- } \\
\text { section }\end{array}$} & EH1 & 540 & 622 & 29.7 & 76.3 & 243 & 259 & 223 \\
\hline & $\mathrm{EH} 2$ & 365 & 477 & 36 & 81.3 & 353 & 347 & 334 \\
\hline & EH3 & 493 & 575 & 27.1 & 77.8 & 252 & 238 & 137 \\
\hline & EH4 & 457 & 550 & 31.0 & 81.3 & 206 & 239 & 203 \\
\hline
\end{tabular}

$\mathrm{R}_{\mathrm{eL}}$, Yield Strength; Rm, Tensile Strength; $\mathrm{A}_{80 \mathrm{~mm}}$, Elongation; Z, reduction of area; IE, impact energy.

\section{Microstructure}

Metallographic microstructure and SEM microstructure at different locations are shown in Fig. 2 3 and Fig. 4 5, respectively. It can be seen that the microstructure of the steel plate mainly consists of polygonal ferrite and composed of carbide-free bainite and pearlite due to the large cooling rate of the steel plate, wherein the volume fraction of ferrite is not less than $90 \%$ with the grain size about $20 \mu \mathrm{m}$, and the pearlite size is less than $10 \mu \mathrm{m}$. The pearlite strips are banded along the rolling direction, and the grain diameters are sequentially increased, which is why the performance of the three steel sheets is sequentially decreased. The microstructures of the $\mathrm{EH} 2$ normalized rolled plate are ferrite and pearlite. The grain size is smaller than that of EH1 steel plate, which proves that the impact toughness of steel plate obtained by rolling and normalizing treatment of EH2 process is the best among all temperatures, as shown in Fig. 2-3 (a), (b) and Fig. 45 (a), (b). Meanwhile, the polygonal or quasi-polygonal ferrite matrix has many similar granular materials, which are easily regarded as granular bainite or precipitates of microalloying elements. The cross-sectional structure area of the yellow mark in Fig. 6(a) was enlarged, and the particulate matter was analyzed by energy spectrum analysis (Fig. 6b). As shown in Figure 5, most of the particulate matter is a ferrite matrix showing only minimal amounts of $\mathrm{Nb}$ and Ti precipitates. The trial of the four steel plates are added micro-alloying elements $\mathrm{Nb}$ and $\mathrm{Ti}$; these alloying elements will form carbonitride precipitates of $\mathrm{Nb}$ and $\mathrm{Ti}$ with $\mathrm{C}$ and $\mathrm{N}$ in steel. Such compounds in the austenite through strain induced precipitation in the dislocation line, the repeated recrystallization of austenite will cause grain refinement, which will produce more dislocations and grain boundaries. Furthermore, the small $\mathrm{Nb}$ and $\mathrm{Ti}$ carbonitrides precipitate on these dislocations and then pin them, which significantly impedes the movement of the recrystallized grain boundaries after deformation. These can refine the austenite grain in recrystallization zone. However, the grain refinement is the one way to improve the strength and toughness of the plasticity at present. It also proves that the mechanical properties of EH1 are better than those of the other three steel plates. Meantime, this paper 
found that the microhardness was in the range of $150 \sim 200 \mathrm{HV}$, within a reasonable range of error. It can be concluded that the ferrite region in the electron microscopic picture is suspected to be a particulate matter caused by the corrosion of the sample. As the ferrite matrix has different orientations, the corrosion resistance of the situation is different. The Corrosion-resistant of ferrite points or surfaces is highlighted during corrosion, while the point or surface of the not corrosion-resistant ferrite is recessed, resulting in electron microscopy picture of ferritic grains similar to the granular material [9]. The fact is that both of them have the same organization, that is, the ferrite matrix.

In order to better reflect the mechanical properties of the steel plate, the impact fracture morphology of the two kinds of steel plates, EH3 and EH4 were analyzed at -20 ${ }^{\circ} \mathrm{C},-40{ }^{\circ} \mathrm{C},-60{ }^{\circ} \mathrm{C}$ as shown in Fig.7. It indicates that the low-temperature impact port morphology of these two kinds of steel plates are a typical ductile fracture, composed of dimples of different sizes, which have a relatively deep size and prove that both of these plates have good plasticity. The dimple size of EH3 steel plate is generally larger than that of EH4 steel plate, which testified that the mechanical properties of EH3 are better than EH4. There are a lot of white granular substances in Fig. 7 (a) and (d). Analyzing by energy spectrum (see Fig 7 a-1 a-2 and d-1 d-2), these particles belong to Al and Mn inclusions, and the low-temperature impact toughness of steel plate will be greatly affected by the size, quantity, and distribution of inclusions in these steels. The number of EH3 inclusions is generally less than that of EH4 inclusions by comparing the lowtemperature impact fracture morphology of these two steel plates.

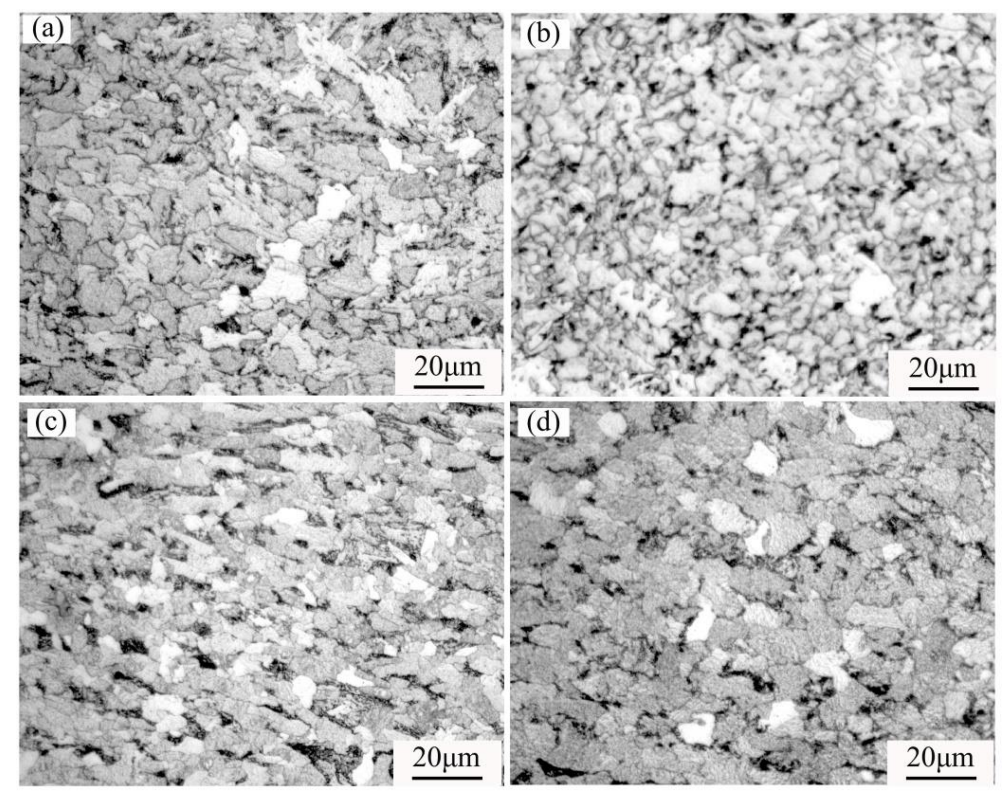

Fig. 2. Cross-section metallographic microstructure of high-strength ship plate steel EH40. (a)EH1, (b) EH2, (c)EH3, (d)EH4. (White and gray parts of the figure for the ferrite structure, the black part for the pearlite structure). 


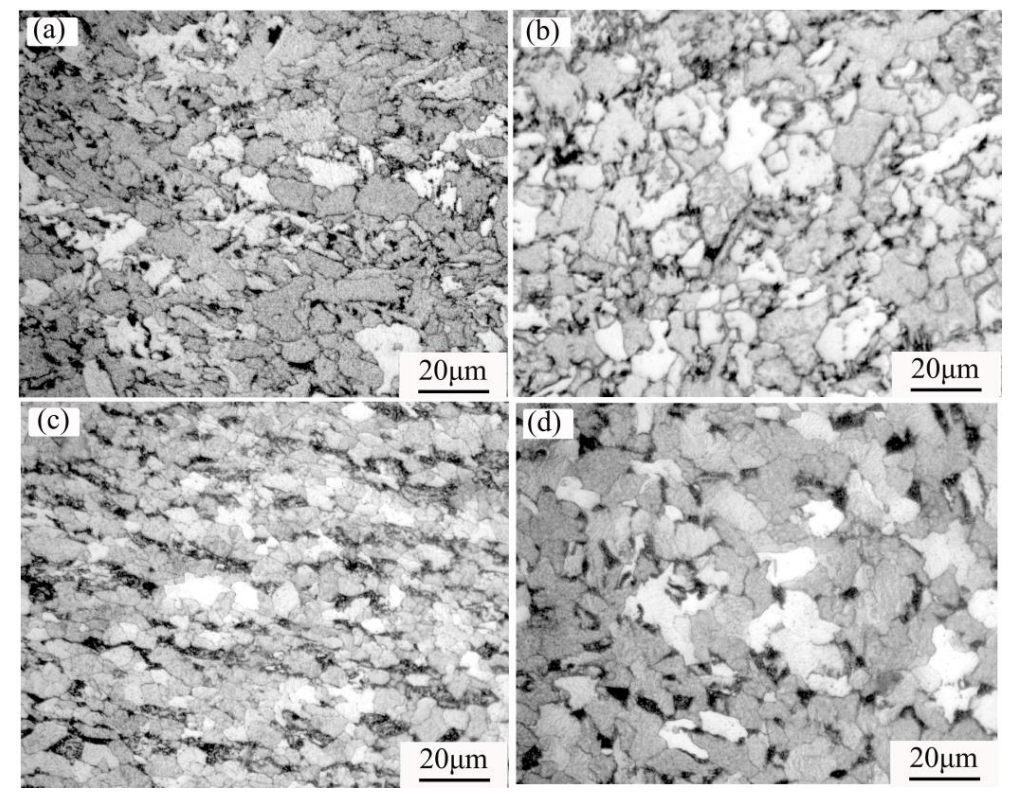

Fig. 3. Vertical-section metallographic microstructure of high-strength ship plate steel EH40. (a)EH1, (b) EH2, (c)EH3, (d)EH4.
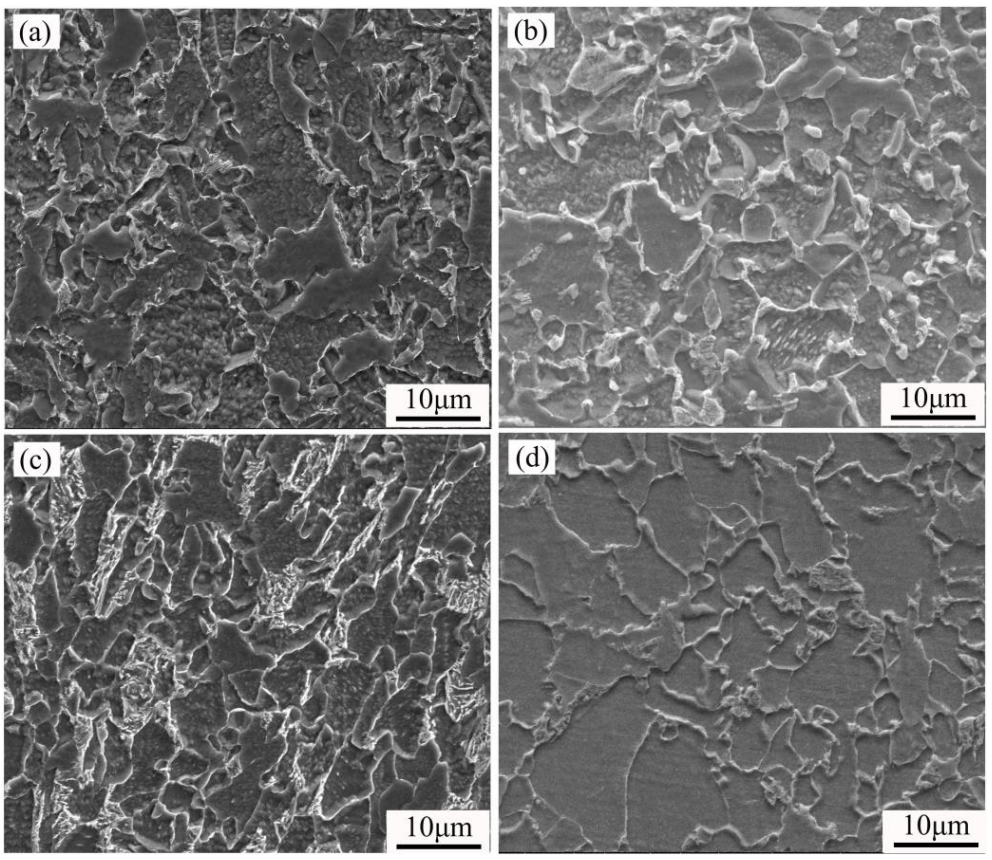

Fig. 4. SEM microstructure of cross-section of high strength ship plate steel EH4O. (a)EH1, (b) EH2, (c)EH3, (d)EH4. 

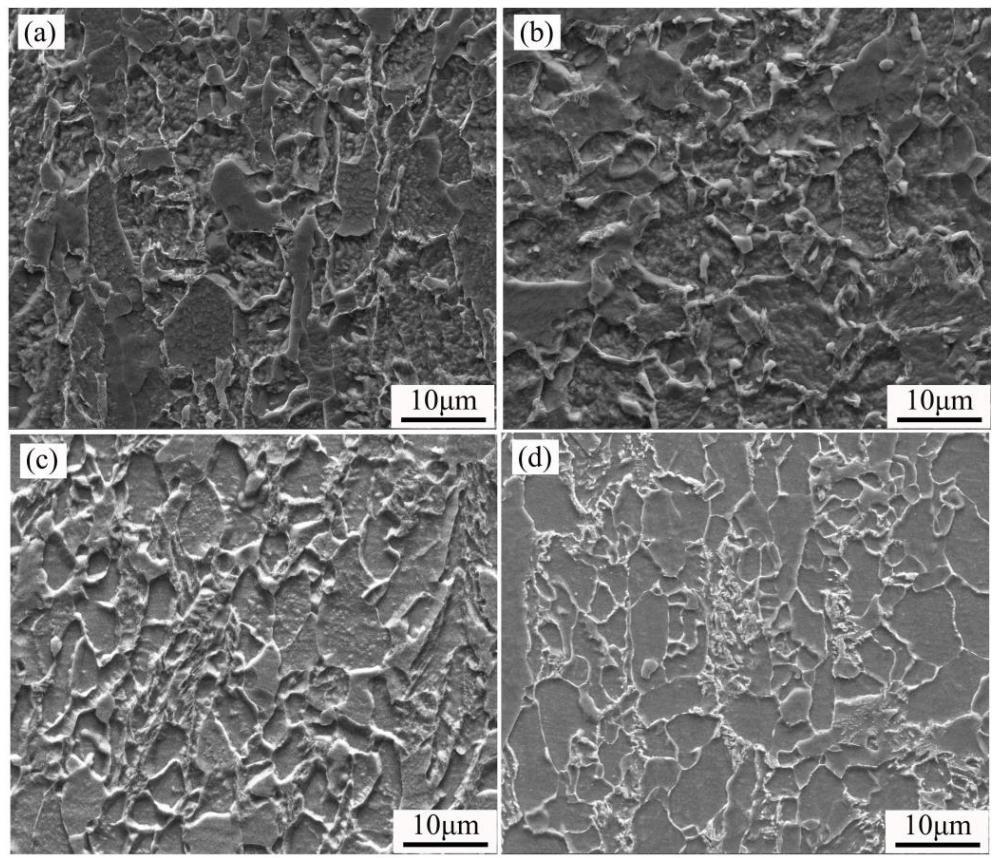

Fig. 5. SEM microstructure of vertical-section of high strength ship plate steel EH4O. (a)EH1, (b) EH2, (c)EH3, (d)EH4.

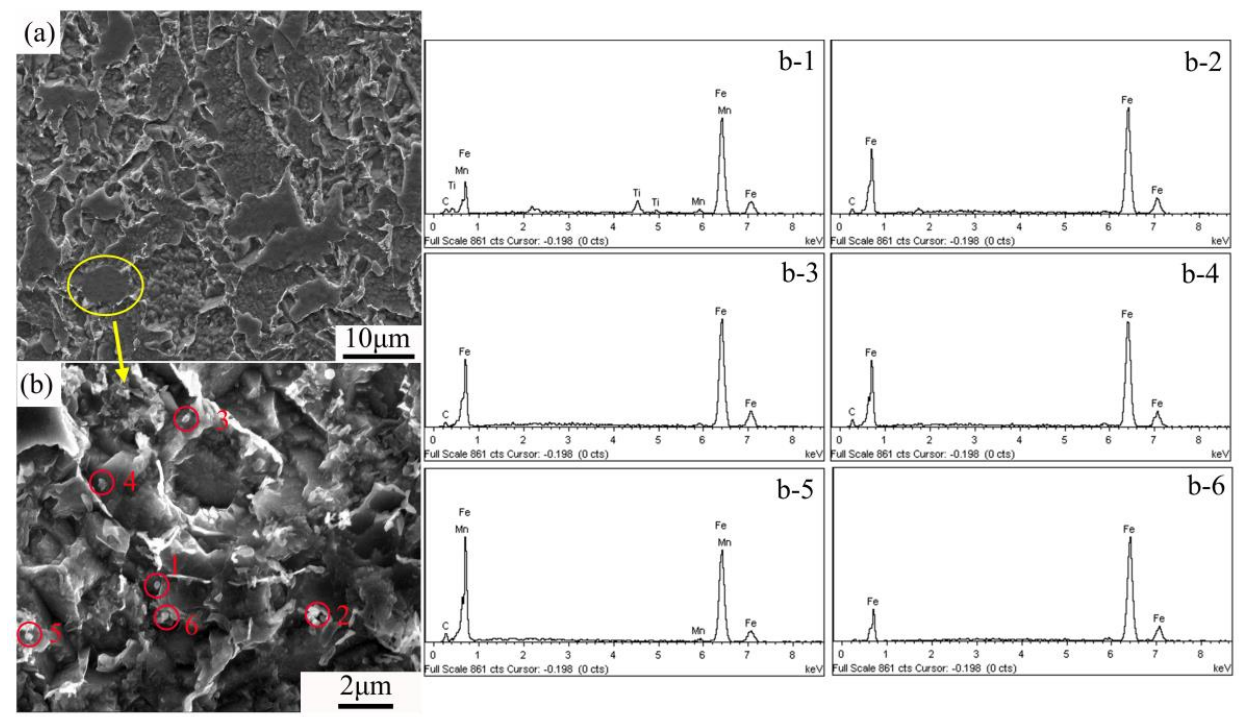

Fig. 6. Energy spectrum analysis of the different points in the cross section of EHI rolled steel sheet (a) SEM microstructure, (b) magnification of the area indicated by $a$ yellow circle in (a), $b-1 \sim b-6$ is the energy spectrum in $(b)$. 


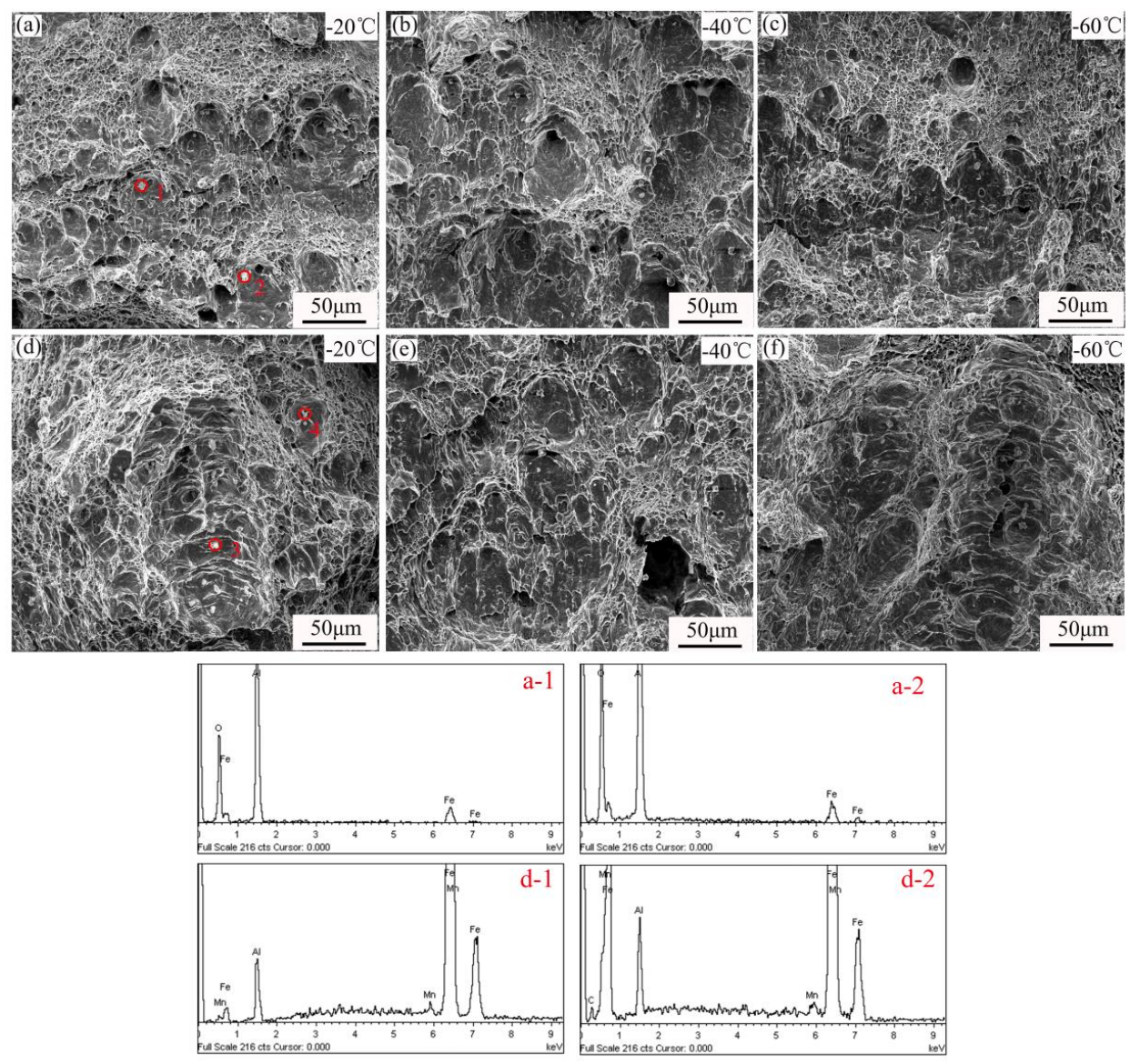

Fig. 7. Impact fracture morphology at different temperatures. $(a) \sim(c) E H I,(d) \sim(f)$ $E H 2, a-1 \sim a-2$ is the energy spectrum in $(a), d-3 \sim d-4$ is the energy spectrum in $(d)$.

\section{Conclusions}

1) The tensile properties and impact toughness of the test steels under different processes are not very different in the transverse-longitudinal directions, As long as the performance in the transverse direction satisfies the requirements, the performance in the longitudinal direction will also meet the requirements.

2) The rolling and normalizing treatment steel of EH2 has better elongation and impact toughness at different temperatures, but its yield strength and tensile strength are lower than the national standard level, which does not meet the requirements.

3) The best process: heating temperature is $1200{ }^{\circ} \mathrm{C}$, the rolling temperature is $1180^{\circ} \mathrm{C}$, the thickness of the ship plate steel is attenuated from $170 \mathrm{~mm}$ to $40 \mathrm{~mm}$ in the recrystallization zone by multi-channel times deformation, and the thickness is changed from $40 \mathrm{~mm}$ to $15 \mathrm{~mm}$ in non-recrystallization zone, the temperature waiting for range is $980{ }^{\circ} \mathrm{C} \sim 920^{\circ} \mathrm{C}$, the ultimate rolling temperature is $830^{\circ} \mathrm{C}$. After rolling, rapid cooling by laminar cooling, the cooling rate is about $12{ }^{\circ} \mathrm{C} / \mathrm{s}$ and the final target temperature is 
$600{ }^{\circ} \mathrm{C}$. The process can be used to obtain the best performance and meet the requirements of the national standard EH40 high-strength ship plate steel while can meet the actual production needs.

4) The microstructure of the EH40 steel plate produced by the best process is mainly polygonal or quasi-polygonal ferrite, and there are a few pearlite structures, the low-temperature impact fracture morphology is a typical ductile fracture.

\section{References}

[1] Q. Shuai: Metall Inform Rev, 5 (2005), 5-8.

[2] L.X. Niu: Wisco Tech, 44 (2006) 48-50.

[3] S. Das, A. Ghosh, et al: Scripta Mater, 48 (2003) 51-57.

[4] H. Zhang, Y.T. Lei, J.S Wei: Steel Structure, 19 (2004) 38-40.

[5] D.T Jiao: China Steel, 15 (2014) 18-20.

[6] China Shipbuilding Industry Association, China Water Transport. 30 (2014) 36-39.

[7] C.Y Zhang, Z.H Xu, S Ga: Baosteel Tech, (2015) 18-22.

[8] X.M Xiao, Y Peng, Y.H Lou, et al: Chinese Journal of Mechanical Engineering, 49 (2013) 97-104.

[9] R. M Wang. Wuhan University of Science and Technology, 2011.

\section{(c) (7) Creative Commons License}

This work is licensed under a Creative Commons Attribution 4.0 International License. 